\title{
No association between major depression with and without childhood adversity and the stress hormone copeptin
}

\author{
Michael Kaczmarczyk , Carsten Spitzer , Katja Wingenfeld , Klaus \\ Wiedemann, Linn K. Kuehl , Katharina Schultebraucks, Christian Eric \\ Deuter \& Christian Otte
}

To cite this article: Michael Kaczmarczyk , Carsten Spitzer, Katja Wingenfeld , Klaus Wiedemann, Linn K. Kuehl , Katharina Schultebraucks, Christian Eric Deuter \& Christian Otte (2020) No association between major depression with and without childhood adversity and the stress hormone copeptin, European Journal of Psychotraumatology, 11:1, 1837511, DOI: $\underline{10.1080 / 20008198.2020 .1837511}$

To link to this article: https://doi.org/10.1080/20008198.2020.1837511
(c) 2020 The Author(s). Published by Informa UK Limited, trading as Taylor \& Francis Group.

Submit your article to this journal
Published online: 02 Nov 2020.

LII Article views: 283 


\title{
No association between major depression with and without childhood adversity and the stress hormone copeptin
}

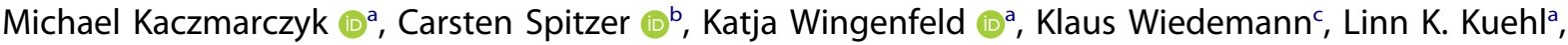 \\ Katharina Schultebraucks ${ }^{d}$, Christian Eric Deuter ${ }^{a}$ and Christian Otte ${ }^{a}$
}

aDepartment of Psychiatry and Psychotherapy, Campus Benjamin Franklin, Charité, Universitätsmedizin Berlin, Corporate member of

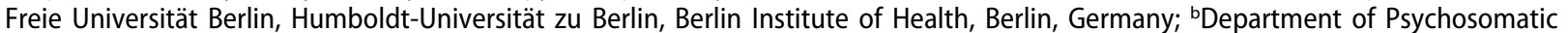
Medicine, University Medicine Rostock, Rostock, Germany; 'Department of Psychiatry and Psychotherapy, University Medical Center Hamburg-Eppendorf, Hamburg, Germany; dVagelos School of Physicians and Surgeons, Department of Emergency Medicine, Columbia University Irving Medical Center, New York, NY, USA

\section{ABSTRACT}

Background: Adverse childhood experiences (ACE) are associated with an increased risk of major depressive disorder (MDD) and hypothalamic-pituitary-adrenal (HPA) axis dysregulation. Within the HPA axis, corticotropin-releasing hormone and vasopressin (AVP) synergistically stimulate the release of adrenocorticotropic hormone, which promotes cortisol release. The cleavage product copeptin is produced during AVP synthesis and is a surrogate marker of AVP release. Children with ACE and young adults with depressive symptoms have higher levels of copeptin than healthy controls.

Objective: To uncover the effects of MDD and ACE on copeptin levels in adult females. Methods: We recruited 94 women (mean age: $34.0 \pm 3.6$ years): 23 with MDD and ACE, 24 with MDD without ACE, 22 with ACE without MDD, and 25 healthy controls. ACE was defined as repeated sexual or physical abuse at least once a month over at least one year before the age of 18 years. MDD was defined by the DSM-IV criteria. Copeptin plasma levels were measured with an immunoluminometric assay.

Results: The four groups did not differ in demographic variables. We found a significant negative correlation between body mass index (BMI) and copeptin plasma levels $(r=-.21$; $p=.045)$. Copeptin plasma levels did not differ between the four groups after controlling for BMI.

Conclusion: Neither MDD nor ACE was associated with altered plasma copeptin levels. Thus, copeptin does not seem to play a major role in MDD and ACE in adult females.

\section{No hay asociación entre la depresión mayor con y sin adversidad infantil y la hormona del estrés copeptina}

Antecedentes: Las experiencias adversas de la infancia (EAI) se asocian con un mayor riesgo de trastorno depresivo mayor (TDM) y desregulación del eje hipotalámico-pituitario-adrenal (HPA). Dentro del eje HPA, la hormona liberadora de corticotropina y la vasopresina (AVP) estimulan sinérgicamente la liberación de la hormona adrenocorticotrópica, que promueve la liberación de cortisol. El producto de escisión copeptina se produce durante la síntesis de AVP y es un marcador sustituto de la liberación de AVP. Los niños con EAI y los adultos jóvenes con síntomas depresivos tienen niveles más altos de copeptina que los controles sanos.

Objetivo: Descubrir los efectos del TDM y la EAl en los niveles de copeptina en mujeres adultas.

Métodos: Se reclutaron 94 mujeres (edad media: $34,0 \pm 3,6$ años): 23 con TDM y EAl, 24 con TDM sin EAI, 22 con EAI sin TDM y 25 controles sanos. La EAl se definió como abuso sexual o físico repetido al menos una vez al mes durante al menos un año antes de los 18 años. El TDM fue definido por los criterios del DSM-IV. Los niveles plasmáticos de copeptina se midieron con un ensayo inmunoluminométrico.

Resultados: Los cuatro grupos no difirieron en las variables demográficas. Encontramos una correlación negativa significativa entre el índice de masa corporal (IMC) y los niveles plasmáticos de copeptina $(r=-.21 ; p=.045)$. Los niveles plasmáticos de copeptina no difirieron entre los cuatro grupos después de controlar el IMC.

Conclusión: Ni el TDM ni la EAI se asociaron con niveles alterados de copeptina plasmática. Por tanto, la copeptina no parece desempeñar un papel importante en el TDM y la EAI en mujeres adultas.

\section{有无童年期不良经历的重性抑郁与应激激素肽素之间没有关联}

背景:童年期不良经历 (ACE) 与重性抑郁障碍 (MDD) 和下丘脑-垂体-肾上腺 (HPA) 轴失调的 风险增加有关。在HPA轴内，促肾上腺皮质激素释放激素和加压素 (AVP) 协同刺激促肾上
ARTICLE HISTORY

Received 9 March 2020

Revised 1 October 2020

Accepted 1 October 2020

\section{KEYWORDS}

Copeptin; stress; major depressive disorder; adverse childhood experiences; body mass index

\section{PALABRAS CLAVE}

Copeptina; estrés; trastorno depresivo mayor;

experiencias adversas de la infancia; índice de masa corporal

\section{关键词}

肽素; 应激; 重性抑郁障碍; 童年期不良经历; 体重指 数

\section{HIGHLIGHTS}

- Copeptin correlated negatively with body mass index in adult females - No association between major depressive disorder and copeptin in adult females

- No association between adverse childhood experiences and copeptin in adult females 
腺皮质激素的释放，从而促进皮质醇的释放。裂解产物肽素是在AVP合成过程中产生的，是 AVP释放的替代标记。具有ACE的儿童和具有抑郁症状的年轻人比健康对照者的肽素水平 更高。

目的:探究成年女性中MDD和ACE对肽素水平的影响。

方法:我们招募了 94 名女性 (平均年龄:34.0 3 .6岁):23名具有MDD和ACE，24名具有MDD无

ACE，22名具有ACE无MDD和25名健康对照。ACE被定义为在18岁之前的至少一年内，每月

至少经历一次的重复性的性虐待或身体虐待。MDD由DSM-IV标准定义。用免疫荧光分析 测定了血浆肽素水平。

结果:四组人口统计学变量无差异。我们发现, 体重指数 (BMI) 与血浆肽素水平之间存在显 著负相关 $(r=-.21 ; p=.045)$ 。控制BMI后，四组之间的血浆肽素水平无差异。

结论:MDD和ACE均与血浆肽素水平的改变无关。因此，肽素在成年女性的MDD和ACE中似 乎没有起主要作用。

\section{Introduction}

Activation of the hypothalamic-pituitary-adrenal (HPA) axis by physiological or psychosocial stressors stimulates the release of corticotropin-releasing hormone (CRH) from the hypothalamus, which in turn stimulates adrenocorticotropic hormone (ACTH) production, thus promoting cortisol secretion. The hypothalamic hormone vasopressin (AVP), synergistically with $\mathrm{CRH}$, stimulates the secretion of ACTH and cortisol (Katan \& ChristCrain, 2010). Measuring CRH and AVP levels to monitor stress-mediated activation of the HPA axis is challenging because they are released in a pulsatile pattern, are biochemically unstable, and are rapidly degraded and cleared from plasma within minutes. The 39 amino acids glycopeptide copeptin, a cleavage product of AVP synthesis, is more stable at room temperature and easier to measure in plasma (Katan \& Christ-Crain, 2010; Morgenthaler, Struck, Alonso, \& Bergmann, 2006; Spanakis, Wand, Ji, \& Golden, 2016). Copeptin levels are elevated in many severe medical conditions, including acute myocardial infarction and stroke (Katan \& Christ-Crain, 2010; Lewandowski \& Brabant, 2016), an effect attributable to increased AVP levels in response to stress.

Research on the link between psychosocial stress and copeptin is just emerging. Median copeptin and median cortisol levels were increased in a group of healthy subjects immediately after the Trier Social Stress Test (TSST) (mean age: 22.5 years) (Siegenthaler, Walti, Urwyler, Schuetz, \& Christ-Crain, 2014). Spanakis et al. (2016) reported higher baseline copeptin levels in men compared with women. After the TSST, the authors found a positive association between the percent change in copeptin levels and cortisol in men, but not in women. Administration of the panicogenic peptide cholecystokinin-tetrapeptide (CCK-4) induced copeptin release, which correlated with panic symptoms and secretion of ACTH and cortisol in non-obese men (mean age: 27.4 years) (Demiralay et al., 2017). In another study, Schinke et al. (2017) measured copeptin after dexamethasone administration and before $\mathrm{CRH}$ administration in the combined dexamethasone/CRH stimulation test. Copeptin levels were higher in obese subjects (mean age: $36.5 \pm 10.0$ years; body mass index (BMI): $41.5 \pm 4.7 \mathrm{~kg} / \mathrm{m}^{2}$ ) than normal-weight controls after dexamethasone administration. In the obese group, copeptin correlated positively with BMI, but not with age. Moreover, copeptin serum concentrations correlated positively with ACTH and cortisol curve indicators in obese men but not in non-obese controls and females, suggesting an interaction of the AVP system with HPA activation in obese men (Schinke et al., 2017).

Investigations of copeptin in stress-related disorders are scarce. Major depressive disorder (MDD) and adverse childhood experiences (ACE) such as abuse and neglect have complex und unfavourable long-term effects on both mental and physical health (Otte et al., 2016), which might be partially explained by HPA axis dysfunction (De Bellis \& Zisk, 2014). Depressive symptoms were associated with copeptin plasma concentrations in young adults (mean age: $24.3 \pm 2.97$ years; female: $52.4 \%$ ), with no differences between men and women (Thomsen et al., 2019). In another study, plasma copeptin concentrations were not significantly different between depressed subjects (mean age: $41.9 \pm 11.2$ years; female: $68.2 \%$ ) and healthy controls (mean age: $40.6 \pm 13.1$ years; female: $64.9 \%$ ), and no association was observed between copeptin and cortisol or ACTH (Krogh et al., 2013). Despite growing evidence for a role of copeptin in psychosocial stress, only one study has investigated whether copeptin is associated with the negative effects of ACE (Coelho et al., 2016), and showed that serum copeptin levels were higher in children with ACE than in children without ACE.

MDD and ACE are associated with sex-specific differences (McLean, Asnaani, Litz, \& Hofmann, 2011). Women show higher prevalence rates for both, as well as higher symptom severity and comorbidity rates (Breslau, 2002). This contrasts with the lack of literature in this field and is underpinned by the vast heterogeneity and inconclusiveness of the available data. Therefore, the primary objective of our full-factorial explorative study was to investigate the association between MDD with and without ACE and copeptin in physically healthy females. Moreover, as most findings were reported in children (e.g. Coelho et al., 2016) or young adults (e.g. Thomsen et al., 2019), we opted for adult women in order to extend the literature in this 
population, since ACE has repeatedly been associated with mental impairments and disorders in later life (Gould et al., 2012; Kaczmarczyk, Wingenfeld, Kuehl, Otte, \& Hinkelmann, 2018; Majer, Nater, Lin, Capuron, \& Reeves, 2010; Pechtel \& Pizzagalli, 2011). We hypothesized that plasma levels of copeptin would be positively correlated with MDD and ACE. Since a body of work shows immediate copeptin changes following a stressor task, a secondary aim was to analyse the effects of acute physiological stress on copeptin using the combined dexamethasone/CRH stimulation test, assuming that cortisol response markers would be positively associated with copeptin.

\section{Methods and material}

\subsection{Participants}

Our participants were part of the sample from a previously published study (Spitzer et al., 2017), and copeptin data were available for these participants. Ninety-four women were included: 23 with MDD and ACE (MDD +/ACE +), 24 with MDD without ACE (MDD +/ACE -), 22 with ACE but no current or lifetime MDD (MDD - /ACE +), and 25 healthy controls with no current or lifetime mental disorder and with no experiences of abuse (MDD - /ACE -).

\subsection{Clinical assessment}

All participants underwent a comprehensive clinical assessment including the Structured Clinical Interview for DSM-IV axis I and axis II conducted by a consultant psychiatrist or a licenced psychological psychotherapist.

Subjects with MDD met the clinical criteria for a DSM-IV diagnosis of current major depressive episode based on the SCID-I. Exclusion criteria included schizophrenia, schizoaffective and bipolar disorder, depressive episodes with psychotic features, posttraumatic stress disorder, anorexia, and substance dependence. Depression was measured using the Beck Depression Inventory (BDI-II) based on the self-report and clinician-rated Montgomery-Åsberg Depression Rating Scale (MADRS).

ACE was defined as repeated sexual or physical abuse at least once a month over at least one year before the age of 18 years (Heim et al., 2000b). The presence of ACE was determined in clinical interviews. Afterwards, severity was assessed psychometrically using the German version of the retrospective self-rated Childhood Trauma Questionnaire (CTQ) (Bernstein et al., 2003; Wingenfeld et al., 2010). Additionally, all subjects were interviewed using the Early Trauma Inventory (ETI) (Bremner, Vermetten, \& Mazure, 2000; Wingenfeld et al., 2011).
Healthy controls also completed all clinical interviews and self-report questionnaires in the same manner as described above. No participant of either MDD - group had any current or lifetime mental disorder based on DSM-IV criteria. In order to be considered for either ACE - group (i.e. MDD +/ACE - and healthy controls), the participant had to be free of any adverse life event until the date of testing. This was ensured by extensive clinical interviews, checking for each of the main traumatic experiences (for example sexual harassment, physical abuse, accidents, war or natural disasters among many others). In case one participant reported a mild experience it was thoroughly investigated, whether this had any lasting effects or consequences for the subject. If this was the case, the participant was either excluded from participation, or, based on the criteria mentioned above, considered for one of the ACE + groups (resulting in two highly differing ACE +/ACE - groups).

Further exclusion criteria included neurological and severe metabolic, endocrine, or autoimmune diseases, current infections, pregnancy, and a BMI above 30 (since it is widely established that obesity is associated with a plethora of metabolic and endocrine changes).

\subsection{Procedure}

The study took place at the Department of Psychiatry and Psychotherapy (Campus Benjamin Franklin) of Charité - Universitätsmedizin Berlin. Participants were recruited via public postings and through affective disorder units. All subjects provided written informed consent and received monetary remuneration ( $€ 200$ for the whole study). The study was approved by the local ethics committee. Blood samples were collected in the laboratory at 8 a.m. after an overnight fast (blood was taken with participants in the supine position and after rest for the same time before starting).

\subsection{Combined dexamethasone/CRH stimulation test}

In the combined dexamethasone/CRH stimulation test (performed on a separate day) all subjects received dexamethasone (oral; $1.5 \mathrm{mg}$ ) at 11:00 p.m. on the first study day and human CRH (intravenous; $100 \mu \mathrm{g}$ ) at 2:30 p.m. on the second study day. Salivary cortisol was collected using salivettes before $(-60 \mathrm{~min},-30 \mathrm{~min}$, immediately before CRH infusion) and after (+30 min, $+60 \mathrm{~min},+90 \mathrm{~min},+120 \mathrm{~min}$ ) $\mathrm{CRH}$ infusion. Cortisol response markers were baseline to peak (BtP; difference between the mean of the three baseline cortisol measures and the maximum value after $\mathrm{CRH}$ ) and area under the curve (AUC; computed with respect to 
ground) values (for further information see Spitzer et al., 2017).

\subsection{Hormonal measures}

Copeptin: Blood samples with EDTA added were placed on ice, immediately centrifuged at $4^{\circ} \mathrm{C}$, and stored at $-80^{\circ} \mathrm{C}$ until analysis. Copeptin concentrations were measured in the neurobiological laboratory of the Department of Psychiatry and Psychotherapy of the University Medical Centre Hamburg-Eppendorf using an immunoluminometric assay (B.R.A.H.M.S $\mathrm{GmbH}$, Hennigsdorf, Berlin, Germany). Intra- and interassay coefficients of variation were below $4 \%$ and $7 \%$, respectively. The detection limit was $1 \mathrm{pmol} / \mathrm{l}$.

Cortisol: Salivary samples were stored at $-80^{\circ} \mathrm{C}$ until analysis. Concentrations of free cortisol were measured in the neurobiological laboratory of the Department of Psychiatry and Psychotherapy, Campus Benjamin Franklin, Charité - Universitätsmedizin Berlin. Intraand interassay coefficients of variation were below $8 \%$ and $10 \%$, respectively. All samples and standards were measured in duplicates.

\subsection{Data analysis}

Continuous variables were analysed with ANOVA and categorical variables with $\mathrm{Chi}^{2}$ tests. Correlations were tested between copeptin and clinical parameters including age, BMI, clinician- and self-reported depression scales, clinician- and self-reported childhood trauma scales, and cortisol response markers of the combined dexamethasone/CRH stimulation test (BtP and AUC values). We performed a $2(\mathrm{MDD}+, \mathrm{MDD}-) \times 2$ (ACE +, ACE -) ANCOVA with BMI as a covariate to analyse main effects and interaction effects on plasma copeptin concentrations.

\section{Results}

\subsection{Sample characteristics}

Demographic and clinical data are shown in Table 1. The four groups did not differ significantly in age, BMI, smoking, years of education, and intake of oral contraceptives. Some women with MDD received antidepressants, but there was no significant difference in medication intake between the non-ACE and ACE group. Psychiatric comorbidities are presented in Table 1. No participants in the MDD - /ACE + group and no healthy controls had a mental disorder according to DSM-IV criteria. The MDD groups did not differ significantly in MADRS and BDI-II scores, but exhibited higher scores than both non-MDD groups did. CTQ and ETI sum scores were higher in both ACE groups than in the non-ACE groups.

Table 1. Sample characteristics of women with MDD with and without ACE and healthy women with and without ACE.

\begin{tabular}{|c|c|c|c|c|c|c|}
\hline & & $\begin{array}{c}M D D+/ A C E+ \\
(N=23)\end{array}$ & $\begin{array}{c}M D D+/ A C E- \\
(N=24)\end{array}$ & $\begin{array}{c}M D D-/ A C E+ \\
\quad(N=22)\end{array}$ & $\begin{array}{c}M D D-/ A C E- \\
\quad(N=25)\end{array}$ & statistics \\
\hline Age & Years & $32.74(10.6)$ & $35.79(10.4)$ & $35.68(11.5)$ & $32.00(11.2)$ & $p=.521$ \\
\hline Years of education & & $11.09(1.5)$ & $11.13(1.4)$ & $11.50(1.3)$ & $11.70(1.3)$ & $p=.420$ \\
\hline Body mass index & $\mathrm{kg} / \mathrm{m}^{2}$ & $22.45(3.3)$ & $22.62(4.2)$ & $24.07(3.3)$ & $21.51(3.2)$ & $p=.108$ \\
\hline Smoking & Yes/No & $11 / 12$ & $8 / 16$ & $6 / 16$ & $6 / 19$ & $p=.317$ \\
\hline Intake of oral contraceptives & Yes/No & $7 / 16$ & $8 / 16$ & $5 / 17$ & $7 / 18$ & $p=.879$ \\
\hline Psychotropic medication & Yes/No & $6 / 17^{a}$ & $6 / 17^{b}$ & $0 / 22$ & $0 / 25$ & $p=.003$ \\
\hline SNRI & & 2 & 3 & & & \\
\hline SSRI & & 2 & 2 & & & \\
\hline NDRI & & 1 & 0 & & & \\
\hline Tricyclic antidepressants & & 1 & 0 & & & \\
\hline Mirtazapine & & 2 & 1 & & & \\
\hline Agomelatine & & 0 & 1 & & & \\
\hline Anticonvulsants & & 1 & 0 & & & \\
\hline \multicolumn{7}{|l|}{ Major depressive episode } \\
\hline MADRS & Sum score & $32.91(6.7)$ & $29.67(6.6)$ & $2.77(2.3)$ & $0.52(0.9)$ & $p<.001$ \\
\hline BDI-II & Sum score & $26.39(10.6)$ & $26.92(8.0)$ & $9.42(7.1)$ & $2.76(3.1)$ & $p<.001$ \\
\hline \multicolumn{7}{|l|}{ Anxiety } \\
\hline STAI trait & Sum score & $47.52(4.7)$ & $48.93(6.1)$ & $42.05(5.9)$ & $41.60(2.4)$ & $p<.001$ \\
\hline \multicolumn{7}{|l|}{ Adverse childhood experiences } \\
\hline ETI & Sum score & $578.61(352.77)$ & $388.20(377.30)$ & $710.05(334.89)$ & $23.80(43.49)$ & $p<.001$ \\
\hline CTQ & Sum score & $62.63(16.3)$ & $46.12(14.0)$ & $65.86(19.2)$ & $28.33(3.5)$ & $p<.001$ \\
\hline Copeptin & $\mathrm{pmol} / \mathrm{l}$ (SEM) & $4.70(0.64)$ & $4.58(1.01)$ & $4.70(0.52)$ & $4.36(0.56)$ & $p=.982$ \\
\hline
\end{tabular}

\section{Abbreviations}

$\mathrm{MDD}+/ \mathrm{ACE}+=\mathrm{MDD}$ subjects with $\mathrm{ACE}, \mathrm{MDD}+/ \mathrm{ACE}-=\mathrm{MDD}$ subjects without $\mathrm{ACE}, \mathrm{MDD}-/ \mathrm{ACE}+=$ subjects with $\mathrm{ACE}$ but no MDD, MDD /ACE $-=$ healthy controls, $\mathrm{BMI}=$ body mass index, $\mathrm{OC}=$ oral contraceptives, $\mathrm{SNRI}=$ serotonin and noradrenaline reuptake inhibitor, $\mathrm{SSRI}=$ selective serotonin reuptake inhibitor, NDRI = dopamine and noradrenaline reuptake inhibitor, BDI-II = Beck Depression Inventory, MADRS = MontgomeryÅsberg Depression Rating Scale, STAI = State-Trait Anxiety Inventory, ETI = Early Trauma Inventory, CTQ = Childhood Trauma Questionnaire, $\mathrm{SEM}=$ standard error of the mean.

Anticonvulsants: pregabalin

${ }^{3} 3$ subjects had 2 drugs.

b 1 subject had 2 drugs.

MDD +/ACE +: 9 subjects reported psychiatric comorbidities (6 subjects with persistent depressive disorder, 2 subjects with panic disorder, 1 subject with social anxiety disorder)

MDD +/ACE -: 8 subjects reported psychiatric comorbidities (2 subjects with agoraphobia, 1 subject with borderline personality disorder, 2 subjects with persistent depressive disorder, 3 subjects with social anxiety disorder) 


\subsection{Correlations between copeptin and demographic variables}

BMI correlated negatively with plasma copeptin $(r=-.21 ; p<.045)$ (Figure $1(\mathrm{a}))$, so we included $\mathrm{BMI}$ in all further analyses. Other demographic variables (including age) did not significantly correlate with copeptin levels.

No psychopathology scores correlated significantly with copeptin (MADRS: $r=-.048$; $p=.653$; BDI-II: $r=-.047 ; p=.663$; STAI trait: $r=-.040 ; p=.707$; ETI: $r=-.039 ; p=.711$; CTQ: $r=-.124 ; p=.243$ ).

\subsection{Effects on copeptin}

$2 \times 2$ ANCOVA with BMI as a covariate did not reveal a significant main effect of $\operatorname{MDD}(F(1,85)=.017$; $p=.895)$ or $\operatorname{ACE}(F(1,85)=.490 ; p=.486)$ on copeptin plasma levels (Figure 1(b)). The interaction between MDD and ACE was not significant $(F(1,85)=.292$; $p=.590)$.

Exploratory analyses for the overall sample revealed a significant negative correlation between copeptin and the cortisol response markers of the combined dexamethasone/CRH stimulation test (BtP: $r=-.231 ; p=.031 ;$ AUC: $r=-.225 ; p=.036)$.

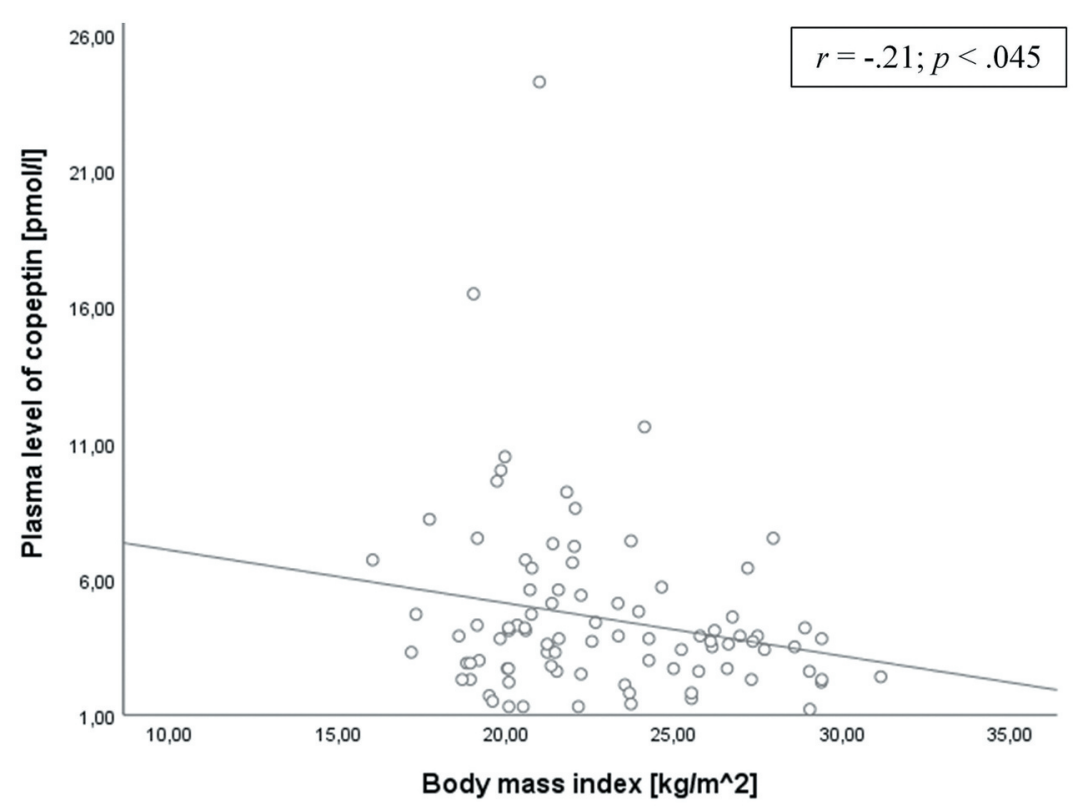

a

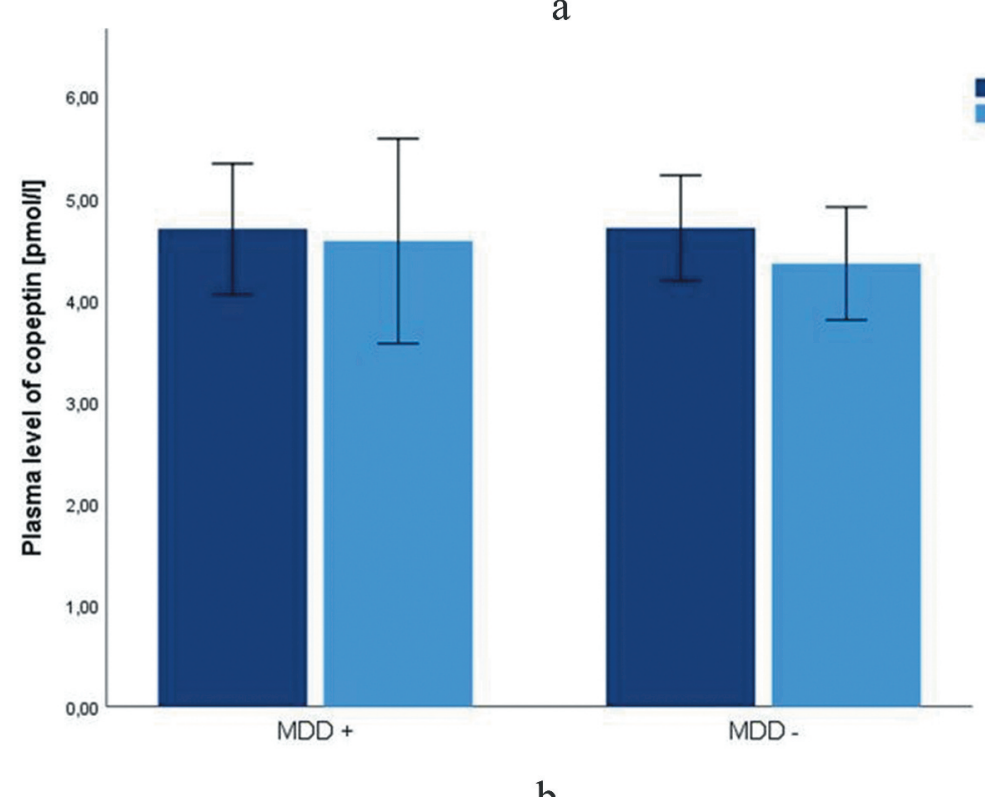

b

Figure 1. (a) Negative correlation between body mass index (BMI) and plasma copeptin levels in the overall sample. (b) Mean plasma copeptin levels. A $2 \times 2$ ANCOVA with BMl as covariate revealed no main effect of MDD or ACE, nor a significant MDD by ACE interaction effect. Depiction of mean value and standard error of the mean. 


\section{Discussion}

In this study, we did not detect any significant association between copeptin and MDD or a history of ACE in an adult, all-female sample.

Our finding that copeptin levels are not altered in individuals with MDD agree with those of Krogh et al. (2013), who found no difference in copeptin levels between depressed patients and healthy subjects. We expand these findings by including ACE in the present study. Our finding that copeptin levels are not altered in individuals with ACE is in contrast to a cross-sectional investigation which showed higher serum copeptin levels in children with ACE compared with controls, independent of age, sex, and symptom severity (Coelho et al., 2016). The design of this previous study was very similar to ours - the inclusion criteria were similar (i.e. good physical health, history of either moderate to severe ACE or no ACE) and the sample sizes of the ACE + and ACE groups were similar too. The similar design suggests that this discrepancy may be explained by an influence of age; this should be investigated in future studies. Another possible explanation could be sex-related differences, as Coelho et al. (2016) included males and females in their study (ACE +: 47.8\% female; ACE - : $52.2 \%$ female) whereas we only included females.

Our all-female sample was different to the mixed samples investigated by Thomsen et al. (2019) and Coelho et al. (2016). Not only basal copeptin concentrations (Burckhardt et al., 2014) but also the effects of stress on copeptin levels (Spanakis et al., 2016) seem to be sex-specific and thus are different in males and females. Copeptin levels were significantly lower in women than men before CCK-4 was applied to induce panic-like symptoms, while men showed a significantly higher increase of copeptin levels after CCK-4 was administered (Kellner et al., 2019). We decided to study an all-female population to eliminate any sex-specific effects and determine whether copeptin levels are altered in female individuals with MDD and ACE.

Copeptin levels correlated negatively with BMI in our study; as BMI increased, copeptin plasma concentrations decreased. In another study, a positive correlation between copeptin levels and BMI was observed in obese males, but not in women and nonobese controls (Schinke et al., 2017).

Exploratory analyses revealed a negative correlation between copeptin levels and cortisol increase (measured by BtP and AUC values in the combined dexamethasone/CRH stimulation test). Schinke et al. (2017) found that copeptin levels (after dexamethasone) correlated positively with ACTH and cortisol release in obese males but not in females.

There are strengths and limitations to our study. We studied a homogeneous sample of female subjects. As described above, all diagnoses ware based on extensive clinical interviews. Our full-factorial study design allowed us to infer conclusions on the differential effects of MDD and ACE. However, we cannot generalize our findings to men. The literature on the association between psychosocial stress and stress-related disorders with copeptin generally shows immediate effects (i.e. following a stressor task) in males. We decided to investigate adult females due to the previously mentioned sex-specific differences in MDD and ACE. Therefore, future studies should further investigate whether affected persons of different sex and age show the same pattern of effects on copeptin. Another limitation is the retrospective assessment of ACE and the cross-sectional design of our study. We measured copeptin on only one occasion. We were thus unable to deduce whether copeptin might be altered in relation to an acute traumatic experience, or if copeptin changes precipitate traumatic events, or if the level of copeptin and the development of psychopathology are in any way related. We assume that the lack of consistency in the field at this point might also be due to the heterogeneity of the methods applied (pharmacologically induced stress (combined dexamethasone/CRH stimulation test), social stressors in laboratory settings (TSST), acute real-life stressful situations (exams, hospital admissions) as well as chronic real-life stressors (childhood maltreatment)) and the varying definitions and measures of MDD and ACE. We also did not measure osmolality; therefore, we could not control for water balance when interpreting copeptin concentrations. Additionally, establishment of normal ranges and as a clinical parameter or biomarker is yet to be implemented.

Research into the association of copeptin with psychosocial stress and mental disorders has just started. It is not yet known whether increased copeptin levels are short-term increases in response to acute stress (state marker) or rather reflect longterm changes (trait marker). Further studies are needed to clarify these issues and to characterize the influence of age and sex on copeptin secretion.

\section{Acknowledgments}

We acknowledge support from the German Research Foundation (DFG) and the Open Access Publication Fund of Charité - Universitätsmedizin Berlin.

\section{Disclosure statement}

$\mathrm{CO}$ has received honoraria for lectures and/or scientific advice from Allergan, Ferring, Fortbildungskolleg, Limes Klinikgruppe, Lundbeck, MedOnline, Medical Tribune, Neuraxpharm, SAGE Therapeutics, and Stillachhaus. All other authors reported no potential conflicts of interest. 


\section{Funding}

The study was supported by German Research Foundation (DFG) grants [WI 3396/6-1 and SP 579/3-1] awarded to KW, $\mathrm{CS}$, and CO. MK participated in the $\mathrm{BIH}$ - Charité Clinician Scientist Program funded by the Charité - Universitätsmedizin Berlin and the Berlin Institute of Health.

\section{ORCID}

Michael Kaczmarczyk (D) http://orcid.org/0000-0003-23665972

Carsten Spitzer (D) http://orcid.org/0000-0002-2711-285X

Katja Wingenfeld (D) http://orcid.org/0000-0001-7457-0370

\section{Data availability statement}

The data that support the findings of this study are available from the authors upon reasonable request (please contact Katja Wingenfeld; katja.wingenfeld@charite.de). The data are not publicly available due to legal and ethical restrictions.

\section{References}

Bernstein, D. P., Stein, J. A., Newcomb, M. D., Walker, E., Pogge, D., Ahluvalia, T., ... Zule, W. (2003, February). Development and validation of a brief screening version of the Childhood Trauma Questionnaire. Child Abuse \& Neglect, 27(2), 169-190.

Bremner, J. D., Vermetten, E., \& Mazure, C. M. (2000). Development and preliminary psychometric properties of an instrument for the measurement of childhood trauma: The Early Trauma Inventory. Depression and Anxiety, 12(1), 1-12.

Breslau, N. (2002). Epidemiologic studies of trauma, posttraumatic stress disorder, and other psychiatric disorders. The Canadian Journal of Psychiatry, 47(10), 923-929.

Burckhardt, M.-A., Wellmann, M., Fouzas, S., Lapaire, O., Burkhardt, T., Benzing, J., ... Wellmann, S. (2014, September). Sexual disparity of copeptin in healthy newborn infants. The Journal of Clinical Endocrinology \& Metabolism, 99(9), E1750-3.

Coelho, R., Levandowski, M. L., Mansur, R. B., da Cunha, G. R., Asevedo, E., Zugman, A., ... GrassiOliveira, R. (2016, October). Serum copeptin in children exposed to maltreatment. Psychiatry and Clinical Neurosciences, 27(2), 434-441.

De Bellis, M. D., \& Zisk, A. (2014, April). The biological effects of childhood trauma. Child and Adolescent Psychiatric Clinics of North America, 23(2), 185-222.

Demiralay, C., Agorastos, A., Yassouridis, A., Jahn, H., Wiedemann, K., \& Kellner, M. (2017, February). Copeptin -A potential endocrine surrogate marker of CCK-4-induced panic symptoms? Psychoneuro endocrinology, 76, 14-18.

Gould, F., Clarke, J., Heim, C., Harvey, P. D., Majer, M., \& Nemeroff, C. B. (2012). The effects of child abuse and neglect on cognitive functioning in adulthood. Journal of Psychiatric Research, 46(4), 500-506.

Heim, C., Newport, D. J., Heit, S., Graham, Y. P., Wilcox, M., Bonsall, R., ... Nemeroff, C. B. (2000, August). Pituitary-adrenal and autonomic responses to stress in women after sexual and physical abuse in childhood. JAMA, 284(5), 592-597.
Kaczmarczyk, M., Wingenfeld, K., Kuehl, L. K., Otte, C., \& Hinkelmann, K. (2018). Childhood trauma and diagnosis of major depression: Association with memory and executive function. Psychiatry Research, 2018(270), 880-886.

Katan, M., \& Christ-Crain, M. (2010, September 24). The stress hormone copeptin: A new prognostic biomarker in acuteillness. Swiss Medical Weekly, 140, w13101.

Kellner, M., Zwanzger, P., Rupprecht, R., Eser, D., Yassouridis, A., \& Wiedemann, K. (2019, December). Copeptin inCCK-4-induced panic in healthy man: Sexual dimorphisms in secretion pattern and panic response, but no correlation of copeptin with panic symptoms. Psychoneuroendocrinology, 110, 104433.

Krogh, J., Gøtze, J. P., Jørgensen, M. B., Kristensen, L. Ø., Kistorp, C., \& Nordentoft, M. (2013, October). Copeptin during rest and exercise in major depression. Journal of Affective Disorders, 151(1), 284-290.

Lewandowski, K. C., \& Brabant, G. (2016, March). Potential Clinical Utility of Copeptin (C-terminal provasopressin) measurements in clinical medicine. Experimental and Clinical Endocrinology \& Diabetes, 124(3), 173-177.

Majer, M., Nater, U. M., Lin, J. S., Capuron, L., \& Reeves, W. C. (2010). Association of childhood trauma with cognitive function in healthy adults: A pilot study. BMC Neurology, 10(1), 61.

McLean, C. P., Asnaani, A., Litz, B. T., \& Hofmann, S. G. (2011, August). Gender differences in anxiety disorders: Prevalence, course of illness, comorbidity and burden of illness. Journal of Psychiatric Research, 45 (8), 1027-1035.

Morgenthaler, N. G., Struck, J., Alonso, C., \& Bergmann, A. (2006). Assay for the measurement of copeptin, a stable peptide derived from the precursor of vasopressin. Clinical Chemistry, 52(1), 112-119.

Otte, C., Gold, S. M., Penninx, B. W., Pariante, C. M., Etkin, A., Fava, M., ... Schatzberg, A. F. (2016, September 15). Major depressive disorder. Nature Reviews Disease Primers, 2, 16065.

Pechtel, P., \& Pizzagalli, D. A. (2011). Effects of early life stress on cognitive and affective function: An integrated review of human literature. Psychopharmacology, 214(1), 55-70.

Schinke, C., Hesse, S., Stoppe, M., Meyer, K., Schmidt, E., Orthgiess, J., ... Then Bergh, F. (2017, April). Post-dexamethasone serum copeptin corresponds to HPA axis responsiveness in human obesity. Psychoneuroendocrinology, 78, 39-47.

Siegenthaler, J., Walti, C., Urwyler, S. A., Schuetz, P., \& Christ-Crain, M. (2014, December). Copeptin concentrationsduring psychological stress: The PsyCo study. European Journal of Endocrinology, 171(6), 737-742.

Spanakis, E. K., Wand, G. S., Ji, N., \& Golden, S. H. (2016, January). Association of HPA axis hormones with copeptin after psychological stress differs by sex. Psychoneuroendocrinology, 63, 254-261.

Spitzer, C., Otte, C., Kuehl, L. K., May, A., Schultebraucks, K., Hellmann-Regen, J., \& Wingenfeld, K. (2017, January). The dexamethasone corticotropin releasing hormone test in healthy and depressed women with and without childhood adversity. Psychoneuroendocrinology, 87, 147-151.

Thomsen, C. F., Dreier, R., Goharian, T. S., Goetze, J. P., Andersen, L. B., Faber, J., ... Jeppesen, J. L. (2019, May). Association of copeptin, a surrogate marker for arginine vasopressin secretion, with insulin resistance: Influence of adolescence and psychological stress. Peptides, 115, 8-14. 
Wingenfeld, K., Driessen, M., Mensebach, C., Rullkoetter, N., Schaffrath, C., Spitzer, C., ... Heim, C. (2011). Die deutsche Version des "Early Trauma Inventory" - Erste psychometrische Charakterisierung eines Interviews zur Erfassung traumatischer Lebensereignisse in der Kindheit und Jugend. Diagnostica, 57(1), 27-38.
Wingenfeld, K., Spitzer, C., Mensebach, C., Grabe, H. J., Hill, A., Gast, U., ... Driessen, M. (2010, November). The German version of the Childhood Trauma Questionnaire (CTQ): Preliminary psychometric properties. PPmP Psychotherapie - Psychosomatik - Medizinische Psychologie, 60(11), 442-450. 